\title{
Relationships between GPP, Satellite Measures of Greenness and Canopy Water Content with Soil Moisture in Mediterranean-Climate Grassland and Oak Savanna
}

\author{
Shishi Liu, Oliver A. Chadwick, Dar A. Roberts, and Chris J. Still \\ Department of Geography, University of California, Santa Barbara 93106, USA \\ Correspondence should be addressed to Shishi Liu, shishi@umail.ucsb.edu
}

Received 11 November 2010; Revised 7 March 2011; Accepted 5 April 2011

Academic Editor: Mehrez Zribi

Copyright (c) 2011 Shishi Liu et al. This is an open access article distributed under the Creative Commons Attribution License, which permits unrestricted use, distribution, and reproduction in any medium, provided the original work is properly cited.

\begin{abstract}
We investigated the impact of soil moisture on gross primary production (GPP), chlorophyll content, and canopy water content represented by remotely sensed vegetation indices (VIs) in an open grassland and an oak savanna in California. We found for the annual grassland that GPP late in the growing season was controlled by the declining soil moisture, but there was a 10-20-day lag in the response of GPP to soil moisture. However, during the early and middle part of the growing season, solar radiation accounted for most of the variation in GPP. In the oak savanna, the grass understory exhibited a similar response, but oak trees were not sensitive to soil moisture in the upper $50 \mathrm{~cm}$ of the soil profile. Furthermore, while we found most VIs to be more or less related to soil moisture, the Visible Atmospherically Resistance Index (VARI) was the most sensitive to the change of soil moisture.
\end{abstract}

\section{Introduction}

Plant-available soil moisture is a key element in ecosystem functioning, since it links energy balance and hydrological cycles, contributes to vegetation composition and richness, and impacts productivity. California's Mediterranean climate is characterized by highly variable winter precipitation and prolonged summer drought, and its vegetation communities are strongly affected by the availability of water, resulting in pronounced annual cycles of growth and senescence [1]. For example, the growing season of annual grasslands typically begins in the wet and cool winter after major rain events and extends to the late spring supported by a declining supply of soil moisture. Given the nature of the hydroclimate regime in California, understanding the response of different plant functional types to soil water availability should be a primary objective of any advanced natural resource management system.

Semiarid savanna in California, which is composed of widely spaced trees, understory grasses, and forbs, is a common land cover type in California. It has been hypothesized that trees and grasses are able to coexist because of either their differences in resource-acquisition potentials or differences in demographic mechanisms, under such disturbances as fires and grazing [2-4]. In general, spatial niche separation in root distributions appears to be more prevalent in arid systems [5], and plant-available moisture, rather than nutrients, may be the main resource limiting plant growth in savannas $[6,7]$. Regardless of the ultimate controls on savanna structure, trees and grasses compete for available soil water, and although grasses are typically superior competitors for water in the upper horizons owing to their relatively shallow and dense root systems, trees are thought to persist because of exclusive access to deeper water [2]. The exchange of carbon dioxide $\left(\mathrm{CO}_{2}\right)$ and water vapor between the atmosphere and plants is controlled in most plants through the opening of stomata, which is driven by a number of environmental factors including the amount of water in soil [8]. The photosynthetic rate will decrease as plants receive the signal of water stress through osmotic adjustment [9]. Deficiencies of water have also been shown to adversely affect chlorophyll production and canopy water content in some plants [10], but not adversely impact chlorophyll production in others $[11,12]$. The correlation between photosynthesis, chlorophyll content and canopy water content with soil moisture therefore varies among 
different types of vegetation. In this study, we investigated the responses of different plant functional types to soil moisture dynamics within California's semiarid oak savanna. Vegetation responses may include many aspects, but here we focused on: (1) $\mathrm{CO}_{2}$ assimilation, as measured by leaf $\mathrm{CO}_{2}$ exchanges, and (2) greenness and canopy water content, as represented by remote sensing vegetation indices (VIs).

There have been many studies of the controls of environmental variables, particularly precipitation, on $\mathrm{CO}_{2}$ exchanges in forests, savannas, and grasslands [13-19]. Many long-term carbon flux studies have concluded that precipitation has a great impact on the interannual variability of primary production, but have often ignored the fact that precipitation is not equal to water available to vegetation. Plant-available soil moisture depends not only on the amount and the timing of precipitation, but also on the hydrological and physical properties of soil. However, few studies have concentrated on analyzing the impact of soil moisture on productivity of vegetation, mainly due to the scarcity of soil moisture data. Knapp et al. [20] evaluated landscape variability in soil-water-plant relations and net primary production (NPP) in tall grass prairie and found that NPP was linearly related with soil water content along two transects $\left(R^{2}=0.66\right)$. Reynolds et al. [21] studied the relationship between rainfall, soil moisture and plant responses, and their results suggested that productivity in deserts did not respond to rainfall events directly but to available soil moisture. Although Xu and Baldocchi's [17] study stated that leaf area index (LAI) explained over $84 \%$ of the variance in gross primary production (GPP) in the Mediterranean annual grassland and the remaining $16 \%$ was attributed to some combinations of vapor pressure deficit (VPD), temperature, radiation, and soil moisture, the direct impact of soil moisture on GPP was not explored. Therefore, it is essential to investigate the relationship between GPP and soil moisture for arid and semiarid ecosystems dominated by different plant functional types on both seasonal and interannual timescales.

Soil moisture dynamics not only affect a plant's carbon assimilation, but also impact canopy properties (such as leaf area, leaf water content, and greenness) through stomatal control and biochemical control $[22,23]$, resulting in variability in vegetation spectral signatures. Although microwave remote sensing has demonstrated the capability for measuring soil moisture [24-26], it is difficult to evaluate how vegetation responds to the change of soil moisture using microwave remote sensing techniques, because vegetation is semitransparent in the spectral region. VIs, derived from optical remote sensing reflectance data, have proven to qualitatively and quantitatively respond to vegetation properties, including chlorophyll content [26-28] and canopy water content $[29,30]$. Because of their sensitivity to changes in vegetation properties, VIs have been related with soil moisture either to estimate soil moisture or to evaluate the extent of water stress. For example, Farrar et al. [31] showed that the Normalized Difference Vegetation Index (NDVI) varied with soil moisture in a concurrent month in southern African savannas. Dennison et al. [32] found a significant nonlinear relationship between soil water availability and equivalent water thickness (EWT) derived from Airborne Visible/Infrared Imaging Spectrometer (AVIRIS) for different vegetation types. While EWT is not a vegetation index, it is highly responsive to changes in leaf area [33]. Studies in the US Corn Belt have also shown a linear relationship between NDVI and soil moisture $[34,35]$. In particular, Adegoke and Carleton [34] found that vegetation indices lagged up to 8 weeks behind soil moisture. In addition, remotely sensed vegetation indices together with surface radiant temperature have also been used to estimate surface soil moisture [36-38]. These results provide evidence that vegetation indices are responsive to soil moisture variations in arid and semiarid areas, but the relationship between vegetation indices and soil moisture is modified by temperature and soil properties. As Rodriguez-Iturbe [39] stated in the vision of the future water resources research "satellite measurements provide us with a wealth of information about the spatiotemporal evolution of vegetation at different scales and under different climatic conditions. Much research needs to be carried out in the development of models which effectively represent the space-time dynamic interaction between climate, soil, and vegetation, especially in water-controlled ecosystem."

In this study, to explore vegetation responses to changes in soil moisture, we evaluated the relationship between soil moisture and GPP, and remotely sensed measures of greenness and canopy water content in a Mediterraneanclimate annual grassland and an oak savanna. Specifically, we addressed the following questions.

(1) How does GPP respond to seasonal soil moisture fluctuations in annual grassland and oak savanna in California? Is soil moisture the major factor determining seasonal variability of GPP for these grassland and oak savanna?

(2) What is the relationship between MODIS-derived VIs and field-measured soil moisture in Mediterraneanclimate grassland and oak savanna? Which index is the most sensitive to the change of soil moisture?

\section{Data and Methods}

2.1. Site Information. We used data from two AmeriFlux sites located in the foothills of the Sierra Nevada in California. One site (Vaira Ranch) is located in an annual open grassland ecosystem, and the other site (Tonzi Ranch) is an of oak/grass savanna, $3 \mathrm{~km}$ away from the open grassland in Varia Ranch. Deciduous blue oaks (Quercus douglasii) dominate the savanna site, and oak trees cover about $40 \%$ of the landscape within a square kilometer of the flux tower. The vegetation under the oak trees and in the open grassland is comprised of cool-season C3 annual nonnative species, including Brachypodium distachyon L., Hypochaeris glabra L., Trifolium dubium Sibth., Trifolium hirtum All., Dichelostemma volubile A., and Erodium botrys Cav [40]. The climate is Mediterranean with high temperatures, low relative humidity, and no rain in summer, but cool and wet winters. Precipitation is concentrated between October and May, with the mean monthly precipitation ranging from $30 \mathrm{~mm}$ to $100 \mathrm{~mm}$ and the mean annual precipitation about 
$559 \mathrm{~mm}$. Detailed descriptions about these two sites have been presented in Xu et al. [41], Baldocchi et al. [42], and $\mathrm{Ma}$ et al. [40]. The soil in the open grassland site is an Exchequer very rocky silt loam (Lithic Xerorthents), with $30 \%$ sand, $57 \%$ silt, and $13 \%$ clay [39]. At the oak savanna site, the soil is classified as Auburn very rock silt loam (Lithic Haploxerepts). It contains $43 \%$ sand, $43 \%$ silt, and $13 \%$ clay [38].

2.2. Data. $\mathrm{CO}_{2}$ and water vapor fluxes were measured at a $30 \mathrm{~min}$ interval using eddy covariance systems. At the savanna site, the $\mathrm{CO}_{2}$ flux was measured both in the understory ( $2 \mathrm{~m}$ above the ground) and overstory $(23 \mathrm{~m}$ above the ground). It is assumed that the overstory tower collected $\mathrm{CO}_{2}$ flux from both oak trees and grasses, while the understory tower primarily measured flux from grassland. GPP was computed by subtracting ecosystem respiration from net carbon exchange, in which ecosystem respiration was derived from nighttime measurements of net ecosystem carbon exchange using flux partitioning methods described by $\mathrm{Xu}$ and Baldocchi [17].

Standard meteorological and soil parameters were measured continuously with an array of sensors. Volumetric soil water content was measured with frequency domain reflectometry sensors, which were placed vertically at depths of 5, 10, and $20 \mathrm{~cm}$ for the open grassland site and 5,20, and $50 \mathrm{~cm}$ for the oak savanna site. LAI of the herbaceous vegetation was measured periodically using destructive sampling methods at intervals of 2-4 weeks [17]. Meteorological data used in this study included precipitation, photosynthetically active radiation (PAR), air temperature, and VPD. At the oak savanna site, PAR, air temperature, and VPD were measured in both the understory and overstory. Phenological dates of the beginning and the end of growing season were based on the data provided by $\mathrm{Ma}$ et al. [40]. Details about the experiment, instruments, data processing, and data quality have been presented by Flanagan et al. [16] and Baldocchi et al. [42].

A composite MODIS time series at $500 \mathrm{~m}$ spatial resolution developed at UC Santa Barbara [43] was analyzed from 2002 to 2006. These data have a 16-day compositing period and preserve the original seven MODIS $500 \mathrm{~m}$ resolution bands while selecting for the pixel within each compositing period that is the most stable for spectral shape and brightness, thereby minimizing the adverse impacts of clouds, aerosols, and the changing viewing geometry on MODIS spectra. Four vegetation indices that are sensitive to chlorophyll content and canopy water content were calculated based on reflectance data, including the Normalized Difference Vegetation Index (NDVI: [44]), the Visible Atmospherically Resistance Index (VARI: [45]), the Normalized Difference Water Index (NDWI: [46]), and the Shortwave Angle Slope Index (SASI: [47]).

2.3. Methods. In our analyses, half hourly measured air temperature, volumetric soil water content, and VPD were averaged during the daytime when PAR exceeded $10 \mu \mathrm{mol} / \mathrm{m}^{2} / \mathrm{s}$, and the measurements of PAR, GPP, and precipitation were accumulated by day for both sites. Soil water content at $10 \mathrm{~cm}$ and $20 \mathrm{~cm}$ was utilized in the analyses of grassland, and soil water content at $20 \mathrm{~cm}$ and $50 \mathrm{~cm}$ was used for the oak tree analyses. We chose soil moisture at a certain depth instead of the average of soil water content at three depths because the difference, in terms of comparing the values, between these two approaches was minimal.

For analyzing relationships between vegetation indices and soil moisture, soil moisture was extracted on the same day as the selected MODIS pixel and it was also averaged within the 16-day period. Vegetation indices were calculated based on the reflectance of the day when the image was taken; detailed information about NDVI, VARI, NDWI, and SASI are presented below.

NDVI is calculated as

$$
\mathrm{NDVI}=\frac{\left(R_{\mathrm{NIR}}-R_{\mathrm{red}}\right)}{\left(R_{\mathrm{NIR}}+R_{\mathrm{red}}\right)},
$$

where $R_{\text {NIR }}$ and $R_{\text {red }}$ represent the reflectance of near infrared and red wavelengths, respectively. NDVI is the most extensively used VI, a good indicator of canopy structure, green biomass, green LAI, and chlorophyll content [48]. However, it is well documented that NDVI saturates at high LAI values and it is also affected by other factors such as soil background, canopy shadows, illumination, and atmospheric conditions [48, 49]. Unlike NDVI, VARI utilizes the difference between green reflectance and red reflectance in response to changes in chlorophyll, and therefore VARI is sensitive to variations of green vegetation fraction, with correction of atmosphere effect. VARI is calculated as

$$
\text { VARI }=\frac{\left(R_{\text {green }}-R_{\text {red }}\right)}{\left(R_{\text {green }}+R_{\text {red }}-R_{\text {blue }}\right)} .
$$

NDWI replaces the red band in the NDVI with the $1240 \mathrm{~nm}$ shortwave infrared (SWIR) band, in order to maximize the spectral expression of water in leaves and to take advantage of high near-infrared reflectance of vegetations and soils. Thus NDWI responds to changes in the water content of a vegetation canopy. It is calculated as

$$
\mathrm{NDWI}=\frac{\left(R_{\mathrm{NIR}}-R_{\mathrm{SWIR}}\right)}{\left(R_{\mathrm{NIR}}+R_{\mathrm{SWIR}}\right)},
$$

where $R_{\text {NIR }}$ and $R_{\text {SWIR }}$ represent reflectance of near infrared and SWIR, respectively.

Whiting et al. [50] demonstrated that the SWIR region could be fitted by an inverted Gaussian function that is highly correlated to moisture content in soils. SASI simulates the general shape of this part of the spectrum, calculated as product of the angle at the SWIR1 (at $1240 \mathrm{~nm}$ ) of MODIS data and the difference of the reflectance at NIR and the SWIR2 (at $1640 \mathrm{~nm}$ ):

$$
\begin{gathered}
\beta=\cos ^{-1}\left(\frac{a^{2}+b^{2}-c^{2}}{2 * a * b}\right) \text { radians, } \\
\text { Slope }=\text { SWIR } 2-\text { NIR, } \\
\text { SASI }=\beta * \text { Slope },
\end{gathered}
$$



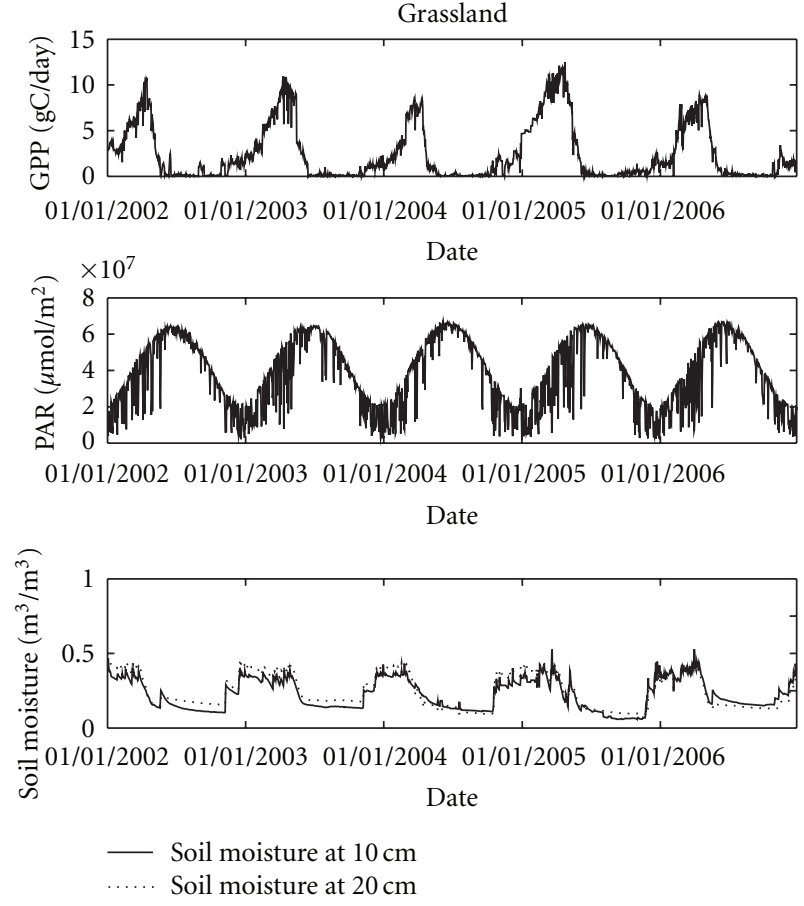

(a)

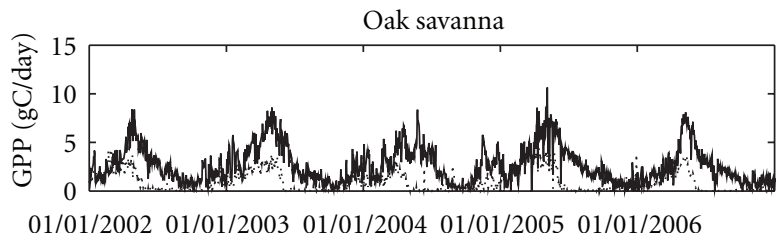

01/01/2002 01/01/2003 01/01/2004 01/01/2005 01/01/2006

Date
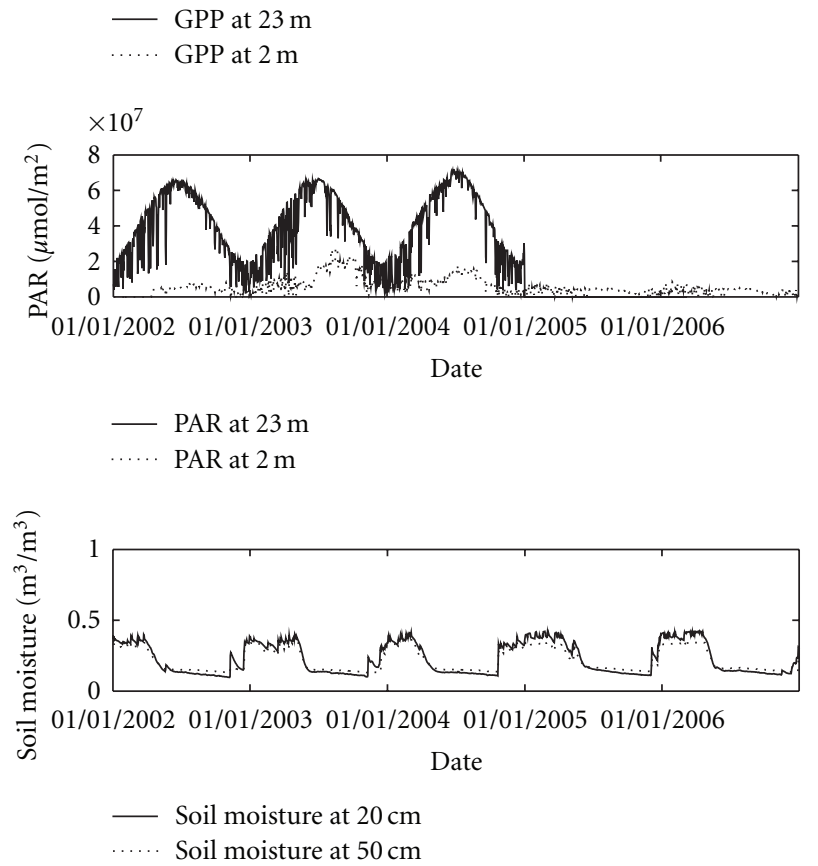

(b)

FIGURE 1: Time series of GPP (gC/day), PAR $\left(\mu \mathrm{mol} / \mathrm{m}^{2}\right)$, and daily soil moisture $\left(\mathrm{m}^{3} / \mathrm{m}^{3}\right)$ at two different depths in the open grassland (a) and the oak savanna (b). where $a, b$, and $c$ are the Euclidian distances between NIR and SWIR1, SWIR1 and SWIR2, and SWIR2 and NIR. Since SASI is based on the SWIR region, it is sensitive to moisture and not photosynthetic activity, revealing different dynamics from NDVI. High positive values characterize dry soils, and high negative values characterize healthy vegetation, while, for the case of plant dry matter, SASI approaches zero [51].

We performed all statistical calculations with MATLAB 7.1. For regression analysis, we used the least-square method, and the probability of significance ( $P$ value) was determined at the significance level of .01. The significance of the correlation between two variables was evaluated using the Pearson correlation coefficient $(r)$ and the coefficient of determination of linear regressions $\left(R^{2}\right)$.

\section{Results}

\subsection{GPP and Soil Moisture in the Grassland and Oak Savanna}

3.1.1. In the Open Grassland. To understand the environmental conditions and the impact of soil moisture on GPP in the open grassland, time series of daily GPP, PAR, and volumetric soil moisture from 2002 to 2006 are shown in Figure 1(a). The invasive grasses at this site typically germinate a week after an autumn rainstorm with total precipitation of at least $15 \mathrm{~mm}$ [17]. At the beginning of the growing season, soil-water resources were sufficient, but the temperature was low and PAR was limited, so the grasses grew slowly, leading to a slow, steady increase in GPP. In the spring, warmer temperature, longer day length, and ample soil moisture contributed to the fast growth of grasses and GPP reached its peak in March or April. Grasses usually maintained peak GPP for a short time of one to two weeks, and then following the rapid decline in soil moisture and an increase in air temperature after peak, GPP declined to zero within two months.

Although grasses respond to increased soil moisture, our analysis shows that, at the beginning of the winter growing season, well before GPP reached its peak, grass growth was not controlled by soil water availability. The relationship between GPP and soil moisture at both depths was negative and weak. This is because the frequent winter precipitation and low evapotranspiration rate at this time led to sufficient soil water, but the low PAR and low air temperature limited photosynthesis, resulting in slow growth and low water demand. However, the soil dry-down curve did coincide with declining grass GPP (Figure 2). Both soil moisture and GPP decreased to a steady state within two months, but the decrease of soil moisture occurred earlier than GPP. Therefore, we assessed the correlation between GPP and lagged soil moisture for each year when they were decreasing. Interestingly, there was a significant linear relationship between GPP and soil moisture lagged by 10 to 20 days in the open grassland site. And the relationship was stronger for soil moisture at $10 \mathrm{~cm}$ than for soil moisture at $20 \mathrm{~cm}$. The lag time was determined based on the maximum correlation coefficients between GPP and lagged soil moisture. Table 1(a) shows the lag between 


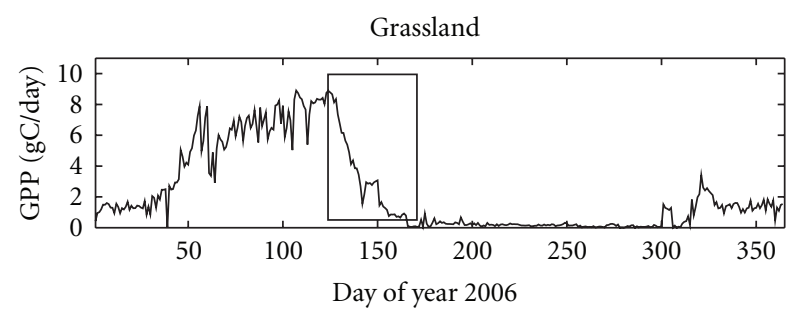

(a)

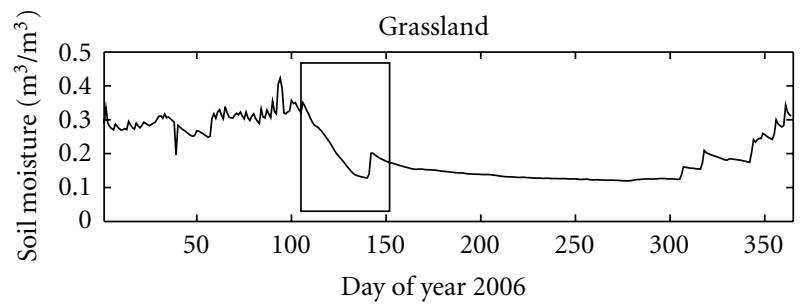

(b)

FIGURE 2: An example of decreasing GPP in agreement with declining soil moisture. Seasonal variation in GPP and soil moisture at $10 \mathrm{~cm}$ in 2006, the highlighted part showing the declines in GPP and soil moisture.

GPP and soil moisture at $10 \mathrm{~cm}$, the regression models, and statistics for the open grassland site.

Autumn rainfall determined the timing of grassland greenup, and frequent rainfall in the spring maintained ample moisture in the soil, ensuring the steady growth of grasses. Years 2002, 2003, and 2006 had moderate amounts of precipitation. We found a significant linear relationship between GPP and a roughly 20-day lagged soil moisture in these three years in the open grassland, indicating the declining rate of grassland productivity was controlled by the dry-down rate of the soil. The small slope of the linear relationship in 2003 was caused by the abrupt drop of GPP on day 136 , from $8.89 \mathrm{gC} /$ day to $3.67 \mathrm{gC} /$ day, and GPP stayed below $4 \mathrm{gC} /$ day after the drop. This decrease in GPP was probably caused by an increase in the daytime mean air temperature from $17.7^{\circ} \mathrm{C}$ on day 135 to $19.5^{\circ} \mathrm{C}$ on day 136 , which led to an increase in VPD. Year 2004 experienced much less precipitation and a longer drought period. The early decrease of soil moisture resulted in a shortened growing season and low annual GPP. Year 2005 was very wet, and the soil maintained high soil water content until the end of May, resulting in a lengthy period of elevated GPP. In 2006, daily GPP in the growing season was less than the other years, with a maximum of $8.9 \mathrm{gC} /$ day, while in the other years, except in 2004, daily GPP was as high as $10.5 \mathrm{gC} /$ day in April. Continuous hot and dry weather following the day when GPP reached its peak of $8.9 \mathrm{gC} /$ day was the main reason that caused the quick decrease of soil moisture as well as GPP. Smaller magnitudes of GPP during the growing season resulted in the smaller slope values in the linear relationship for 2006.

3.1.2. In the Oak Savanna. Environmental conditions in the grassland under the canopy of oak trees are different from the open grassland, primarily because the canopy modifies PAR, air temperature, and VPD (Figure 1). For example, the average annual cumulative PAR beneath the canopy was only $10 \%-30 \%$ of the values in the open grassland. The comparison between soil moisture in open grassland and soil moisture measured under oak trees at the same depth suggests that soil in oak savanna had higher water holding capacity and higher wilting point. The lower GPP in grasses under oak canopies was mainly caused by reduced PAR due to shading, which in turn reduced the photosynthetic rates of grasses. The reduced PAR under the oak canopy substantially limited the extension of leaves as well as photosynthetic activities.

The relationship between declining GPP and lagged soil moisture at the end of spring was still observed in grasses under the oak canopy, but it was less pronounced (Table 1(b)). The lag with the highest correlation between GPP and soil moisture ranged from 5 days in 2003 to 22 days in 2002, differing slightly from the open grassland. This difference was likely caused by the modified radiation and air temperature environment under the tree canopy. It is also likely that the oak trees impacted soil water in ways that affected below-canopy grasses, such as by hydraulic redistribution [52].

The comparison of seasonal variations in oak tree canopy GPP against $50 \mathrm{~cm}$ soil moisture suggests that oak GPP is not controlled by soil water availability in the upper soil horizons. Oak trees in the savanna started to develop leaves in March when soil moisture and light were ample and air temperature was increasing. The leaf expansion stage overlapped with vigorous growth of grasses. Peak oak canopy GPP was achieved in May while the moisture in shallow soil was depleted and the understory grasses were senescing. A substantial portion of the growing season lacked any precipitation and the trees retained leaves for several months until winter arrived. The weak relationship between oak GPP and soil water content in the upper horizons is supported by the findings of others that trees are able to store water and nutrients and to tap water from deeper soil horizons $[53,54]$. The cumulative GPP in the growing season of oak trees for each year did not change much even in the very dry year, indicating that the growth of oak trees is not prone to the short-term environmental changes, presumably due to its very deep root system and possibly some internal storage capability.

3.2. Vegetation Indices and Soil Moisture. In this section, we investigate the impact of soil-moisture fluctuations on the canopy chlorophyll content and water content as represented by different vegetation indices derived from MODIS data. Figure 3 shows the time series of indices and soil moisture at $20 \mathrm{~cm}$ at both sites. NDVI, VARI, and NDWI showed similar responses to the changing soil moisture over the five-year period, while SASI responded in an opposite way. However, changes in the indices were not in phase with the change of soil moisture, similar to the GPP response to the declining soil moisture. At the beginning and the middle part of the growing season (before GPP and VIs decreased), NDVI, VARI, and NDWI were low (SASI was high) and started 
TABLE 1: Regression models and statistics of relationships between GPP and lagged volumetric soil moisture at $10 \mathrm{~cm}$ in open grassland $\left(\theta_{10}\right)$ and at $20 \mathrm{~cm}$ in oak savanna $\left(\theta_{20}\right)$. All the relationships are significant at the $99 \%$ level.

(a) Open grassland

\begin{tabular}{ccccc}
\hline Year & Lag (day) & Period & Regression models & $R^{2}$ \\
\hline 2002 & 18 & $84-125$ & $\mathrm{GPP}=-4.293+44.217 * \theta_{10}$ & 0.94 \\
2003 & 15 & $121-150$ & $\mathrm{GPP}=-1.0791+17.161 * \theta_{10}$ & 0.92 \\
2004 & 24 & $63-101$ & $\mathrm{GPP}=-5.303+42.952 * \theta_{10}$ & 0.73 \\
2005 & 25 & $92-129$ & $\mathrm{GPP}=-4.663+47.295 * \theta_{10}$ & 0.78 \\
2006 & 20 & $96-136$ & $\mathrm{GPP}=-3.070+35.811 * \theta_{10}$ & 0.92 \\
\hline
\end{tabular}

(b) Oak savanna

\begin{tabular}{ccccc}
\hline Year & Lag (day) & Period & Regression models & $R^{2}$ \\
\hline 2002 & 22 & $84-125$ & GPP $=-2.16+0.14 * \theta_{20}$ & 0.79 \\
2003 & 5 & $131-151$ & GPP $=-1.14+0.11 * \theta_{20}$ & 0.60 \\
2004 & 20 & $69-92$ & GPP $=-1.98+0.12 * \theta_{20}$ & 0.52 \\
2005 & 22 & $128-156$ & GPP $=-0.56+0.1 * \theta_{20}$ & 0.34 \\
2006 & 20 & $126-150$ & GPP $=-1.47+0.1822 * \theta_{20}$ & 0.87 \\
\hline
\end{tabular}

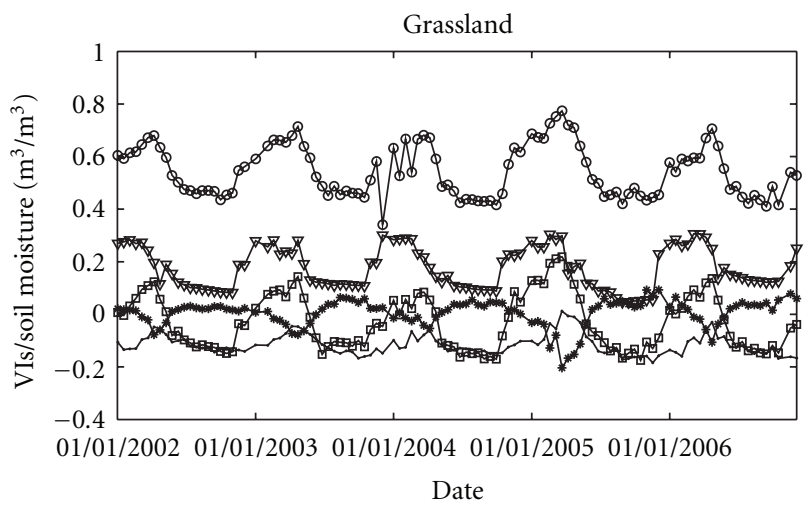

(a)

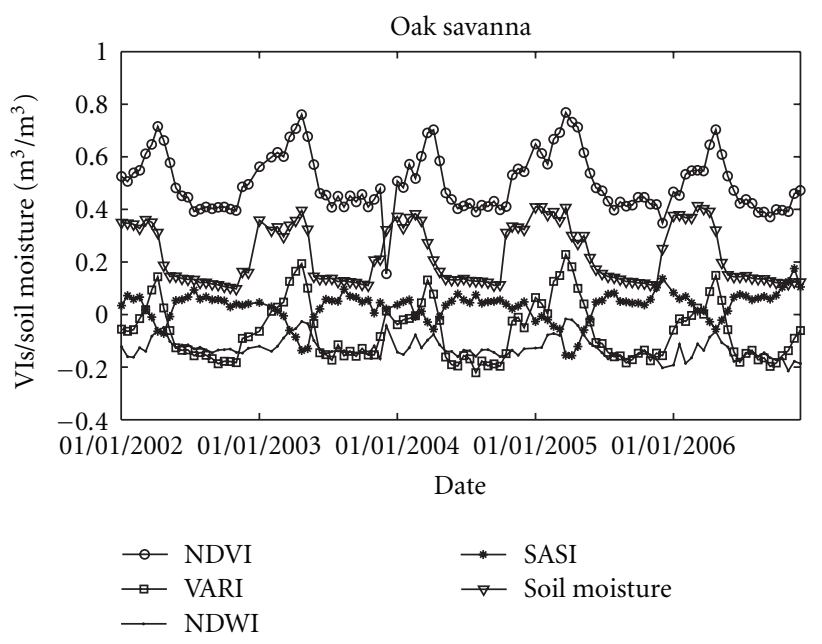

(b)

FIgURE 3: Time series of NDVI, VARI, NDWI, SASI, and soil moisture at $10 \mathrm{~cm}$ in the open grassland (a) and at $20 \mathrm{~cm}$ in the oak savanna (b). to increase (SASI started to decrease) when soil moisture became sufficient. NDVI, VARI, and NDWI began to decline (SASI began to increase) after soil moisture started to drop in the spring. To analyze relationships between four vegetation indices and soil moisture, we evaluated Pearson correlation coefficients $(r)$ between these indices and soil moisture at different depths extracted on the exact day selected for the composite and averaged over the 16-day compositing period (Table 2). The results demonstrate that the four indices are more or less related to soil moisture. Overall, VARI had the strongest relationship at both sites, and VARI increased as soil moisture increased during the five-year study period. The weaker relationships between NDWI/SASI and soil moisture were surprising as one would expect NDWI and SASI to be more responsive to the change of soil moisture because of their sensitivity to the leaf water content. In the open grassland, the relationship was marginally stronger with averaged soil moisture at $10 \mathrm{~cm}$ compared to $20 \mathrm{~cm}$; in the oak savanna, the relationship was slightly stronger with soil moisture at $20 \mathrm{~cm}$.

Interestingly, the curve of the relationship between VARI and 16-day average soil moisture was slightly different in the open grassland and oak savanna site, although at both sites, the relationship can be fitted with a quadratic polynomial statistical function (Figure 4). The relationship in the open grassland was clear and nearly linear, but in the oak savanna, the relationship is more scattered and VARI tends to drop at high soil water content. VARI in the oak savanna site was more variable (variance is 0.21 ) than it was in the open grassland (variance is 0.14 ). VARI changed dramatically in the middle of the growing season of grasses. This is probably because the growing season of Blue Oaks starts later than the grasses in the oak savanna, which may cause the abrupt increase in vegetation indices during the period when trees were greening up and grasses were in the middle of the growing season. In addition, VARI was lower in the oak savanna at the beginning of the growing season when soil 


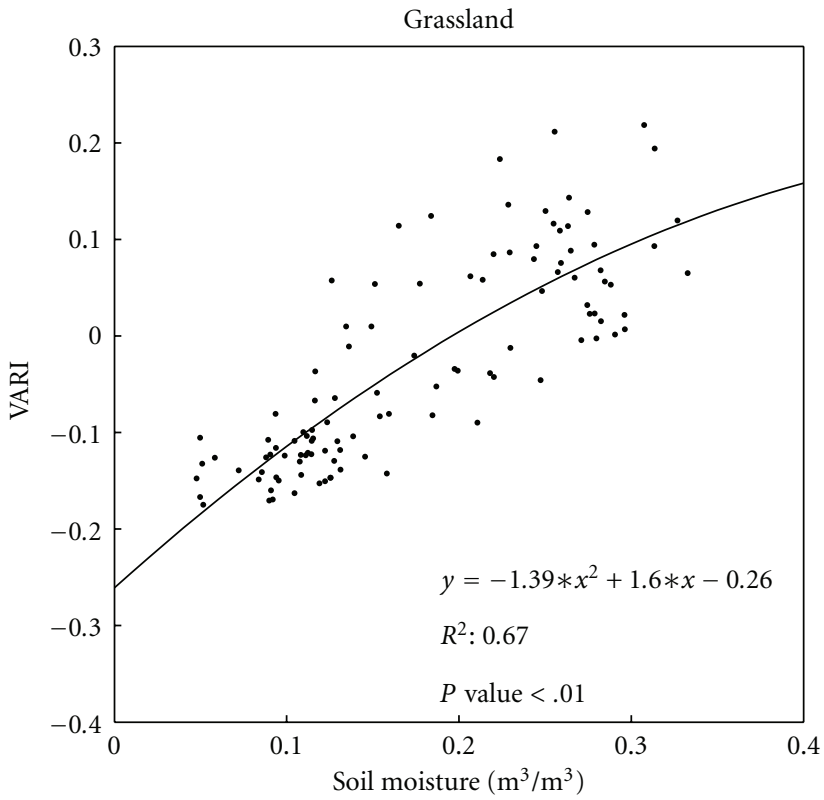

(a)

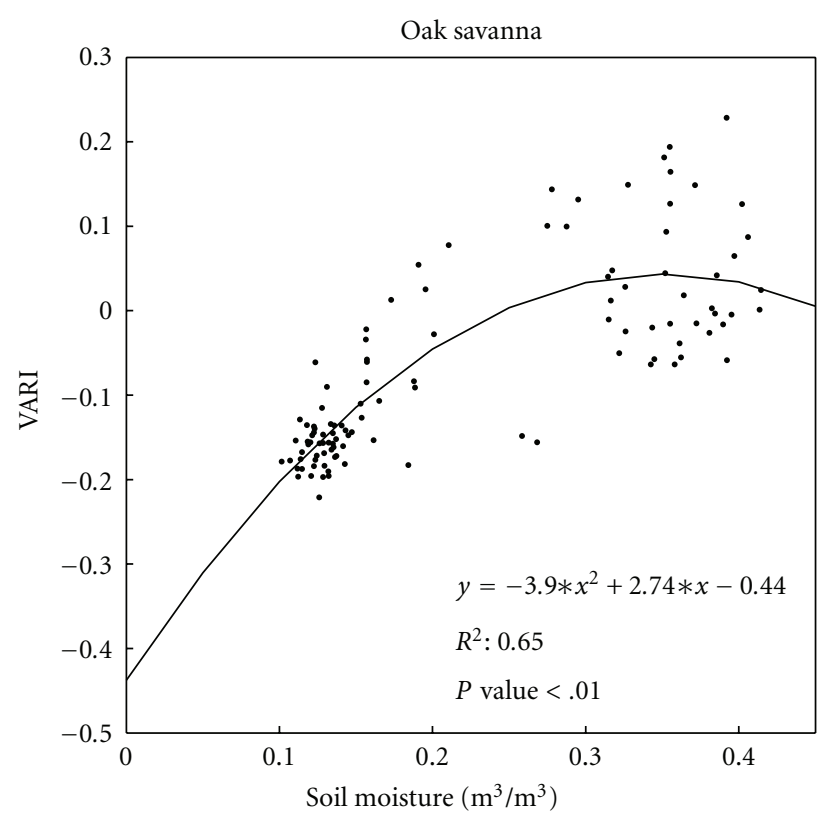

(b)

FIGURE 4: The relationship between VARI and averaged soil moisture at $10 \mathrm{~cm}$ in open grassland and averaged soil moisture at $20 \mathrm{~cm}$ in oak savanna during the same five-year measurement period.

TABLE 2: Correlation coefficients $(r)$ between NDVI, VARI, NDWI, SASI, and instantaneous volumetric soil moisture $\left(\theta_{10}\right.$ and $\left.\theta_{20}\right)$ and 16-day average soil moisture $\left(\theta_{\text {avg_10 }}\right.$ and $\left.\theta_{\text {avg_20 }}\right)$ in the open grassland (a) and oak savanna (b).

(a) Open grassland

\begin{tabular}{lcccc}
\hline & NDVI & VARI & NDWI & SASI \\
\hline$\theta_{10}$ & 0.71 & $\mathbf{0 . 8 1}$ & 0.43 & -0.45 \\
$\theta_{20}$ & 0.69 & $\mathbf{0 . 7 9}$ & 0.41 & -0.43 \\
$\theta_{\text {avg_10 }}$ & 0.74 & $\mathbf{0 . 8 2}$ & 0.46 & -0.48 \\
$\theta_{\text {avg_20 }}$ & 0.72 & $\mathbf{0 . 8 0}$ & 0.44 & -0.46 \\
\hline
\end{tabular}

(b) Oak savanna

\begin{tabular}{lcccc}
\hline & NDVI & VARI & NDWI & SASI \\
\hline$\theta_{20}$ & 0.65 & $\mathbf{0 . 7 9}$ & 0.45 & -0.50 \\
$\theta_{50}$ & 0.61 & $\mathbf{0 . 7 4}$ & 0.40 & -0.44 \\
$\theta_{\text {avg_20 }}$ & 0.69 & $\mathbf{0 . 7 8}$ & 0.41 & -0.49 \\
$\theta_{\text {avg_50 }}$ & 0.67 & $\mathbf{0 . 7 4}$ & 0.38 & -0.45 \\
\hline
\end{tabular}

moisture was sufficient, resulting in a cluster of low VARI at high soil water content. However, further studies about the background effect and the reflectance signature of the oak savanna are needed to explain the variations of vegetation indices in the oak savanna site.

Furthermore, we analyzed the relationships between the indices and soil moisture during the beginning and middle part of the growing season before GPP and VIs began to decrease. We also analyzed the relationships separately during the dry-down and senescence season when soil moisture began to decline and finally became depleted. We did not find significant relationships between any of the indices and soil moisture during the beginning and middle part of the growing season, which explained the scattered pattern shown in Figure 4 as well as the weak relationship for NDWI and SASI. The analysis during dry-down and senescence period revealed a stronger linear relationship between VARI and averaged soil moisture (Figure 5(a)), suggesting that VARI can quantify the change of soil moisture via the change in chlorophyll content when plants are subject to water stress.

Since GPP was linearly related with lagged soil moisture during the dry-down season in the grassland, we evaluated the relationship between the vegetation indices and soil moisture lagged by 0 to 30 days during the dry-down season. A stronger linear relationship between VARI and 17-22-day lagged soil moisture was observed in the open grassland (Figure 6(a)). This result is in agreement with the finding of the strong relationship between GPP and lagged soil moisture from year 2002 to year 2006 during the dry-down season in the open grassland. We also examined the relationship between VIs and soil moisture in the oak savanna during the same dry-down period (Figure 6(b)). Relationships are slightly stronger with 11-day lagged soil moisture. Using lagged soil moisture improved the significance of the relationship between soil moisture and VARI (Figure 5(b)), implying that canopy chlorophyll content is affected by the antecedent soil water status.

The comparison between VARI and NDWI at both sites suggests that the change of NDWI at the beginning of the growing season was slower than the change of VARI. VARI began to increase after the first major autumn rainstorm, which coincided with the phenology data provided by 

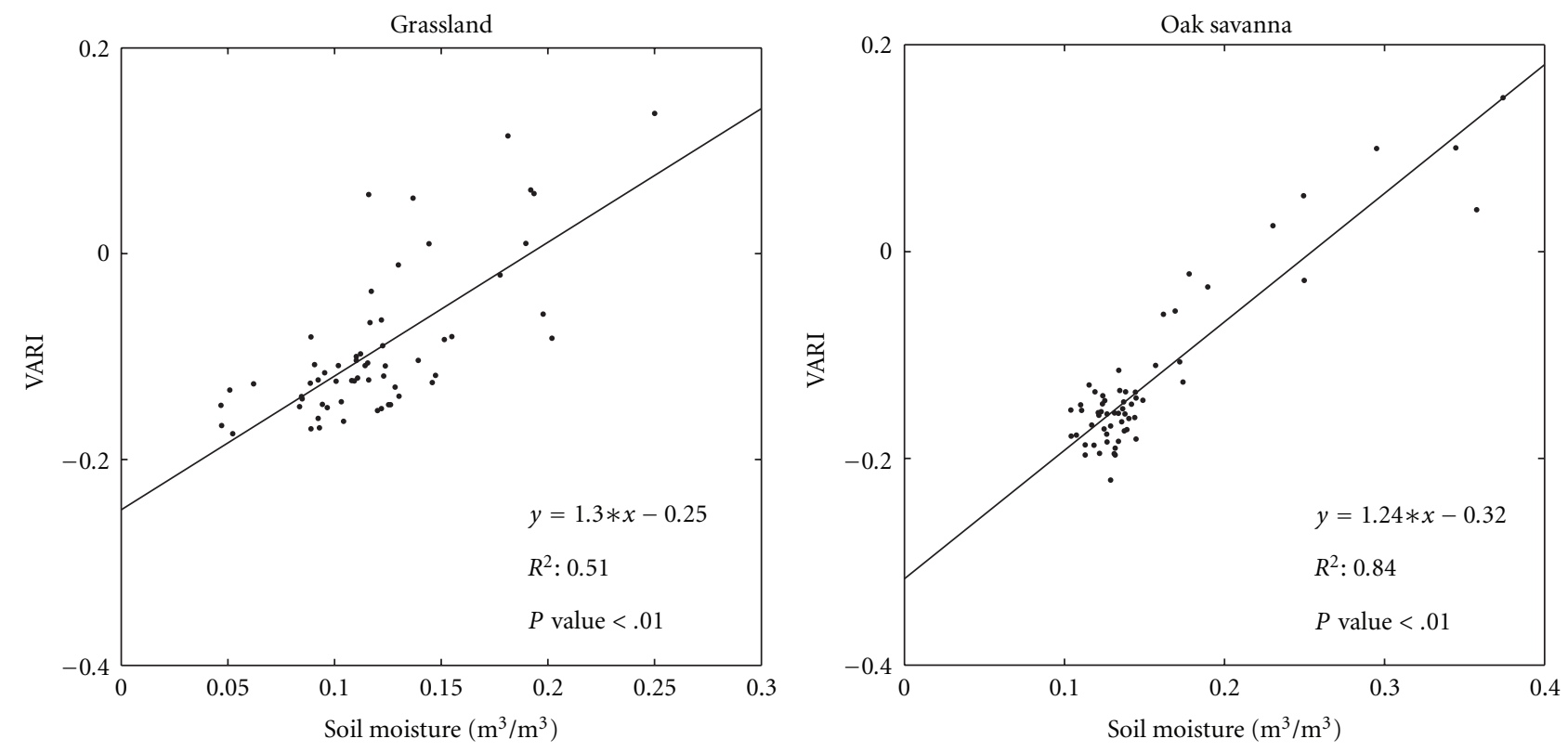

(a)
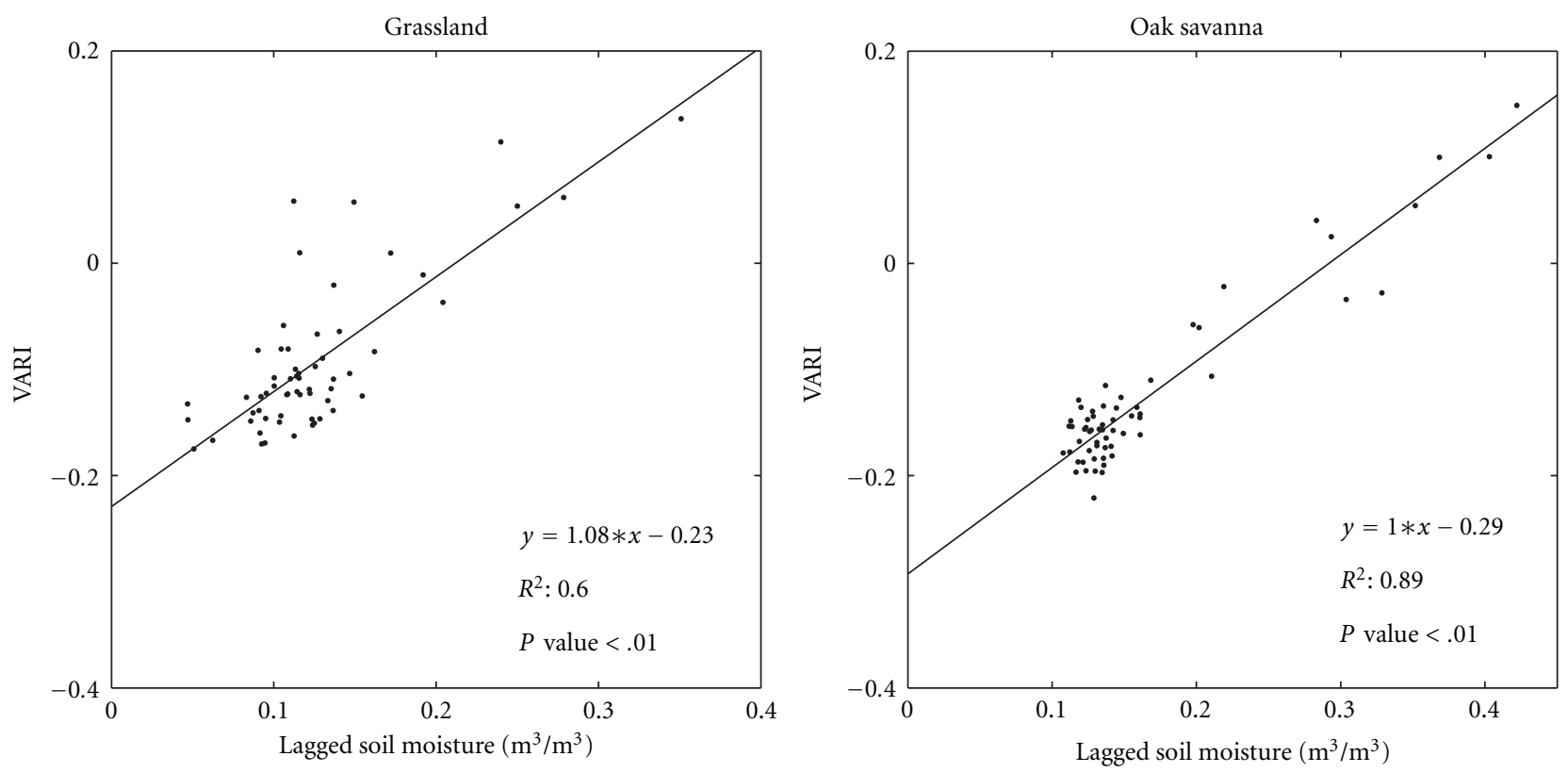

(b)

FIgURE 5: The relationships between VARI and averaged soil moisture (a), lagged soil moisture (b) at $10 \mathrm{~cm}$ in the open grassland and at $20 \mathrm{~cm}$ in the oak savanna during the dry-down and senescence season.

Ma et al. [40], while NDWI did not respond to the change of canopy until January. This explained the significant relationship, particularly in the open grassland, between NDWI and soil moisture during the five-year period.

\section{Discussion}

4.1. Environmental Controls on GPP. GPP was weakly correlated with soil moisture during the beginning and middle part of the growing season, but was strongly correlated with soil moisture lagged up to 25 days during the dry-down period. To investigate factors other than soil moisture that controlled GPP, we evaluated the relationships among GPP and PAR, air temperature, precipitation, and VPD by calculating the correlation coefficients $(r)$ in the open grassland and in the grassland under oak canopy. At both sites, PAR and air temperature were strongly correlated with GPP during the beginning and middle part of the growing season before GPP began to decline. However, the regression model between air temperature and GPP was less 


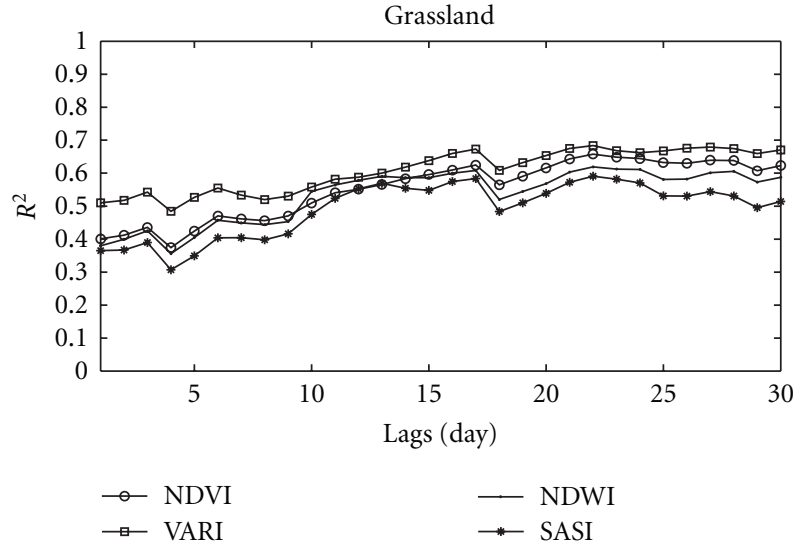

(a)

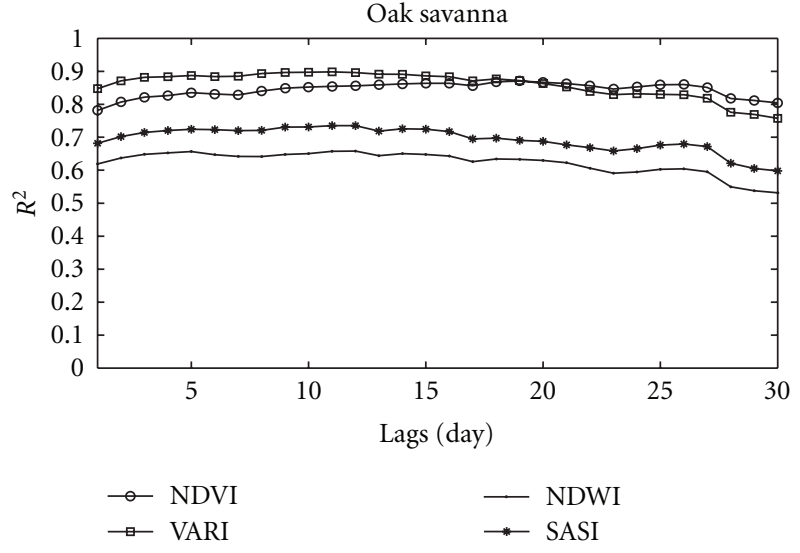

(b)

Figure 6: The correlation coefficients between VIs and soil moisture lagged up to 30 days at $10 \mathrm{~cm}$ in open grassland (a) and at $20 \mathrm{~cm}$ in oak savanna (b) during the dry-down and senescence season.

significant in comparison to the correlation between PAR and GPP, indicating the stronger control of PAR on GPP. Figure 7 shows the linear relationship between GPP and PAR during the beginning and middle part of the growing season. Outliers highlighted in Figure 7 revealed the pulses of GPP in response to specific rainfall events when GPP increased abruptly on the sunny day right after the rainfall in the open grassland site.

Grasses responded slowly to the change of soil moisture, in comparison to their responses to VPD. During the late growing season, after GPP reached its peak, VPD was negatively correlated with GPP, explaining from 20\% (in 2002) to $57 \%$ (in 2004) of the variability in GPP. However, GPP was also observed to decrease because of cool weather, with low temperature and low PAR, even though the precipitation events had occurred several days before and supplied sufficient water.

The impact of environmental variables on the GPP of oak trees was not significant. PAR accounted for only $20 \%$ of the variability in GPP in the growing season. At the beginning of the growing season, pulses of GPP in response to specific rainfall events were observed. After the rain stopped, the GPP of oak trees was negatively correlated with air temperature in the dry season, which accounted for $60 \%$ of the variability in GPP of oak trees. The impact of VPD on stomatal conductance and thus leaf photosynthesis and GPP was more obvious in the middle of the growing season (between April and July), when water in the soil was becoming limited. During this period, VPD was negatively correlated with GPP, explaining about $40 \%$ to $48 \%$ percent of the variability of GPP. GPP usually decreased as soon as VPD reached above $2.0 \mathrm{kPa}$ and when air temperature exceeded $19^{\circ} \mathrm{C}$.

4.2. The Soil Effect on the Relationships between Vegetation Indices and Soil Moisture. Based on the previous analyses, VIs derived from MODIS data respond to the change in soil moisture, particularly in the open grassland, because a change in soil moisture may induce a change in leaf water content as well as a change in chlorophyll concentration and leaf internal structure [55]. Factors that may confound the relationship between soil moisture and a change in a VI are the combined impacts of the amount of exposed soil and green vegetation density within the pixel. In an early stage of vegetation development, green LAI is low and exposed soil or senesced plant material may be high. In this case, the change in substrate albedo associated with a change in soil moisture may significantly modify pixel reflectance $[56,57]$. At maximum LAI, the amount of exposed soil is low, and VIs would be expected to be the least sensitive to changes in substrate albedo and most sensitive to a change in leaf water content or chlorophyll content. To evaluate a potential impact of exposed soil- and soil-moisture-related changes in substrate albedo, the VI-soil-moisture correlation was analyzed at low LAI (0.4-0.5 for the open grassland and 0.1-0.2 for the grassland under oak canopy at the beginning and the end of the growing season) and at the high LAI (2.0-2.5 for the open grassland and 1.0-1.5 for the grassland under oak canopy). At low LAI, the relationships between VIs and soil moisture were weak, suggesting that soil-moisturerelated changes in albedo were minimal on normalized vegetation indices as shown by $[57,58]$. In contrast, strong linear relationships between NDVI/VARI and soil moisture were observed at both sites when LAI was high (Figure 8). This result implies that when leaves are fully developed, the chlorophyll content and leaf area are highly sensitive to the change of soil moisture. The linear relationships are more pronounced in open grassland than in oak savanna, where oak trees are not developing in phase with grasses and confounding the reflectance signal.

\section{Conclusions}

In this paper, we explored the responses of a grassland and an oak savanna to changing soil moisture based on five years of flux tower and meteorological data, along with MODIS imagery for the same period. Analysis of the relationship 


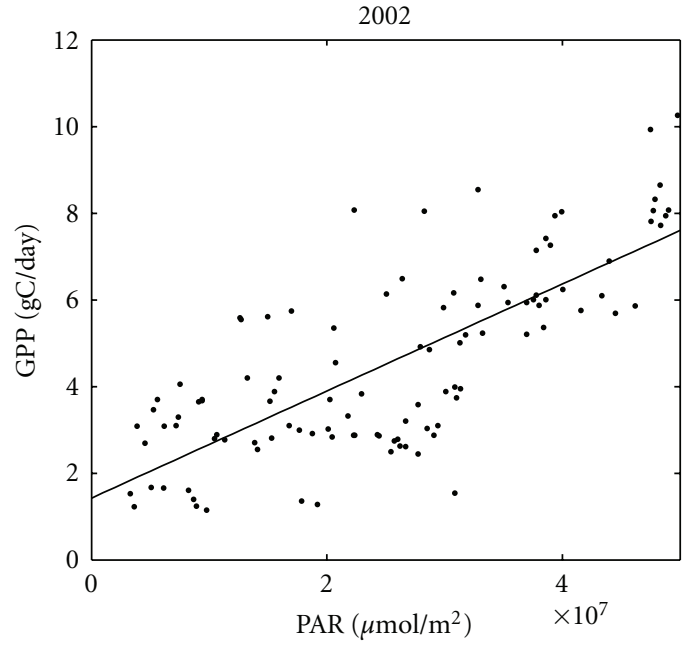

(a)

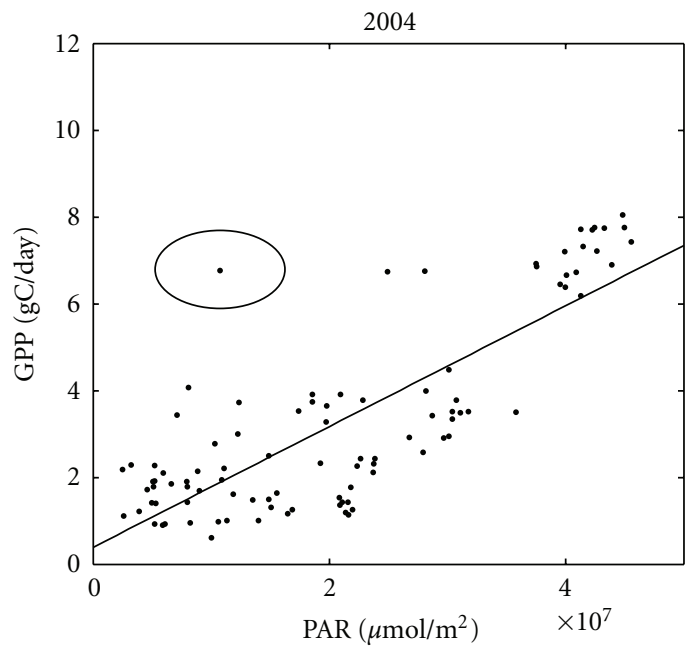

(c)

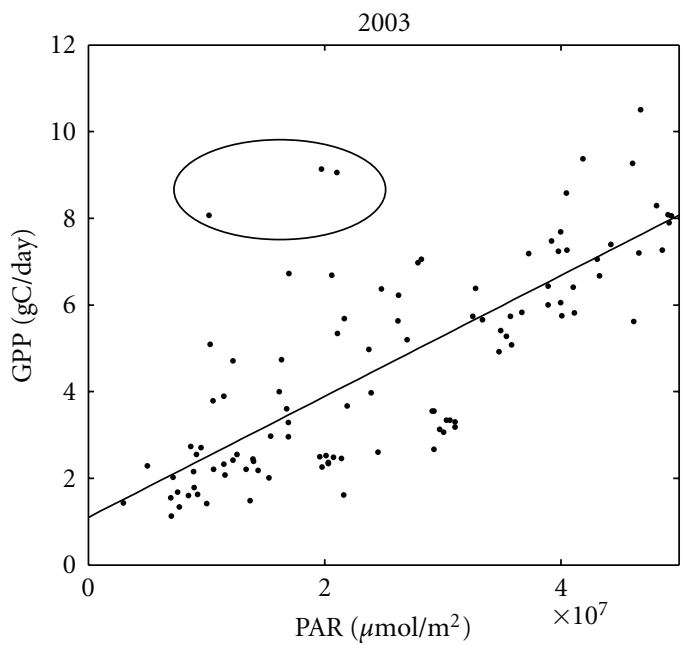

(b)

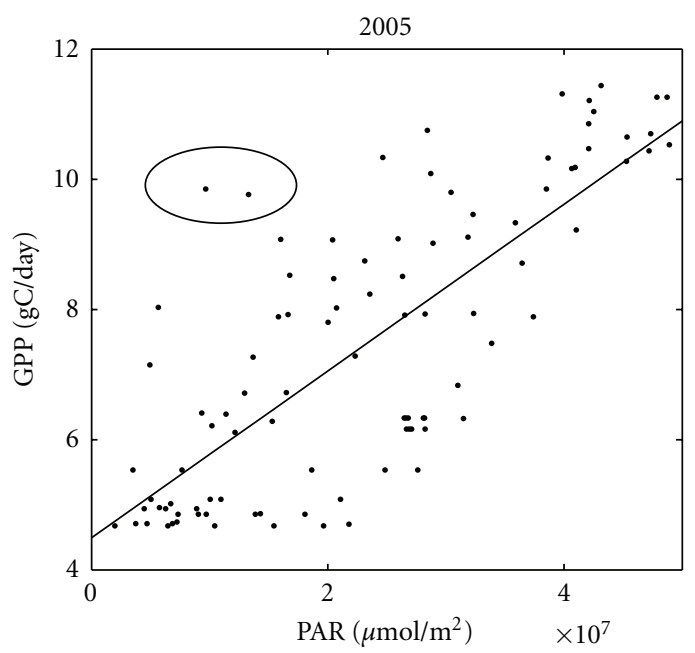

(d)

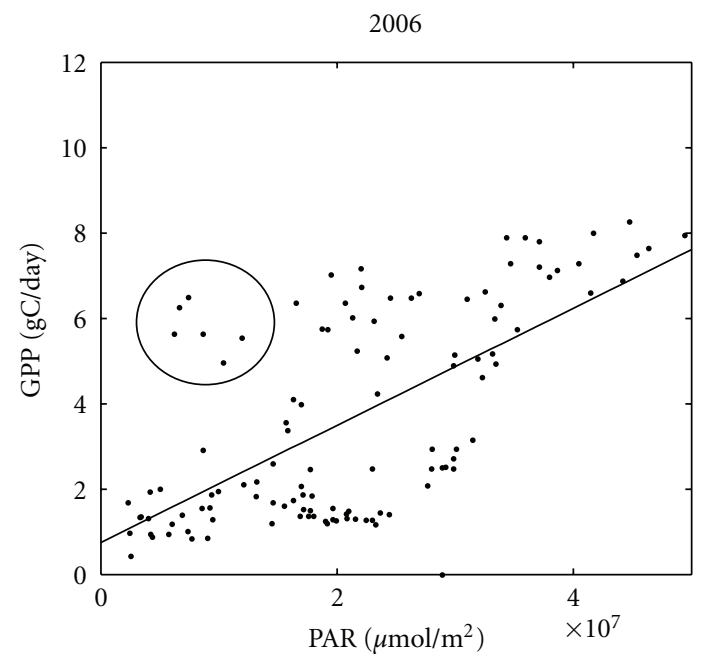

(e)

FIGURE 7: The relationship between daily PAR and GPP in the growing season of the open grassland before GPP declined. Pulses due to rain events are highlighted by circles. 

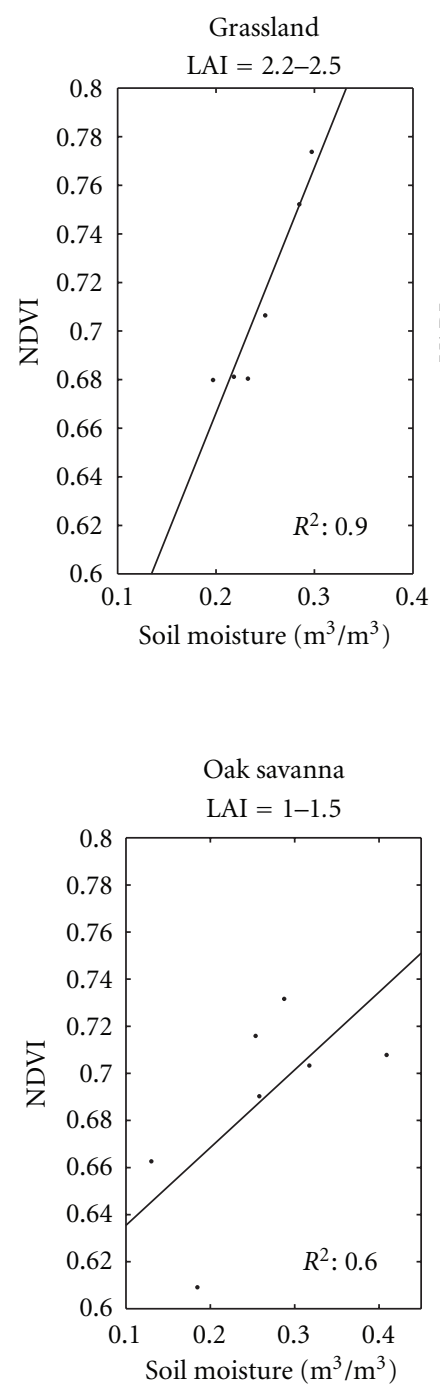

Grassland

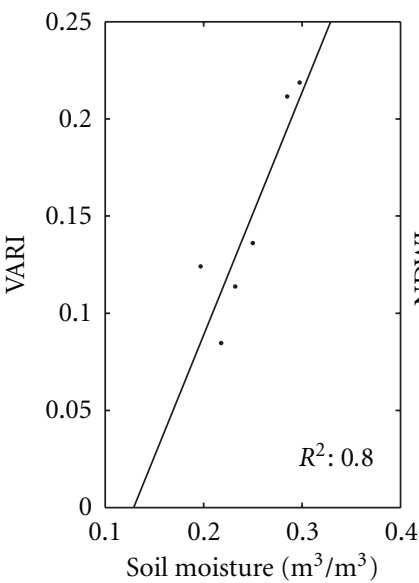

Grassland

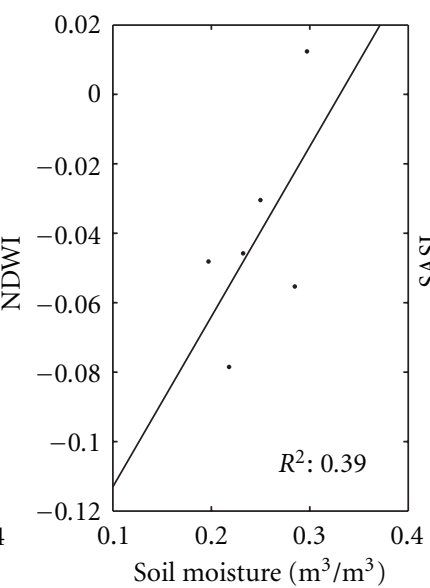

Grassland

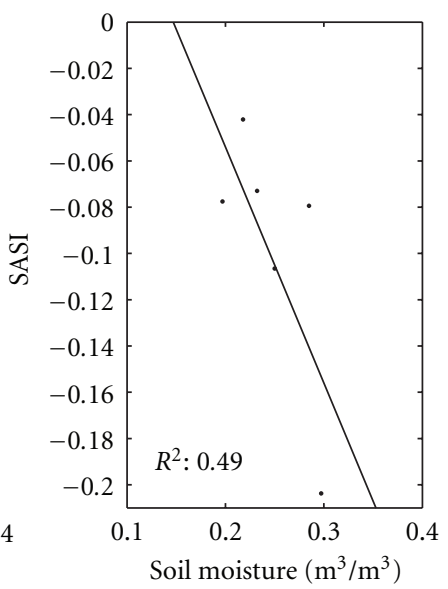

(a)

Oak savanna

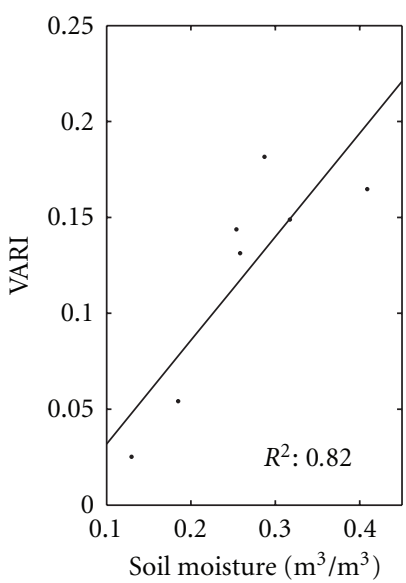

Oak savanna

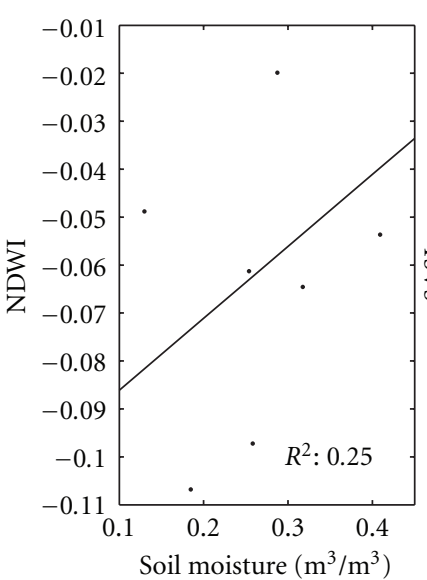

Oak savanna

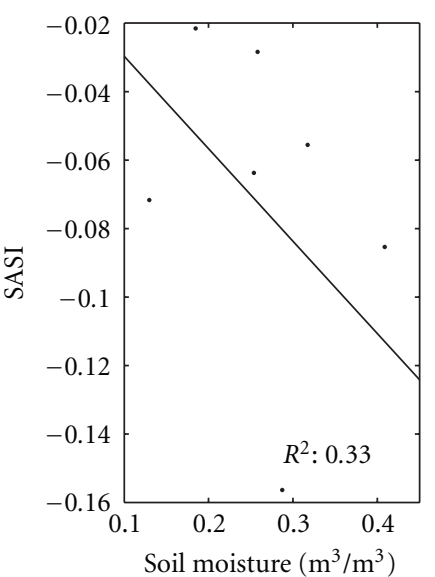

(b)

Figure 8: Relationships between vegetation indices and averaged soil moisture at $10 \mathrm{~cm}$ in the open grassland (a), and at $20 \mathrm{~cm}$ in the oak savanna (b) when LAI reached its maximum at each site.

between soil moisture and GPP in open grassland and oak savanna showed that in annual grasslands, the senescence rate of grasses was controlled by the declining rate of soil moisture, but with a 10-20-day lag between GPP and soil moisture. This result implies that GPP during the late growing season is affected by antecedent soil water availability. However, during the beginning and middle part of the growing season, the build-up toward maximum GPP was largely controlled by PAR, which drives photosynthesis, surface sensible and latent heating, and air temperature. Although GPP during the late growing season in understory grasses was still linearly correlated with antecedent soil moisture, the relationship was weaker than in the open grassland. The phenology of the Blue oak canopy is somewhat divorced from the rainfall cycle; this species leafs out in March and senesces in October or November, and thus missing the initial stages of the annual soil moisture recharge while remaining photosynthetically active after the soil dry-down period. The annual GPP of oak trees did not vary across years, and even in the extreme dry year 2004, the annual oak GPP only decreased $2.1 \%$ in comparison to the GPP in prior, normal rainfall year (2003).

To investigate the impact of soil moisture on canopy chlorophyll content and water content, we assessed the relationships between soil moisture and four VIs derived from MODIS imagery. Overall, grass NDVI and VARI had a stronger relationship with soil moisture during the drydown and senescence season, when the leaf water content and greenness were the most sensitive to changes in soil moisture. Furthermore, as expected, VIs were linearly correlated with lagged soil moisture during the dry-down period. The analysis of the relationship between VIs and soil moisture at low grass LAI value demonstrated that normalized reflectance reduced the soil background effect which resulted from the change of soil water content. However, at the highest LAI value, when grasses are fully developed, chlorophyll 
content was highly responsive to the change of soil moisture, leading to strong relationships between NDVI/VARI and soil moisture.

Although this study was based in California, the results should be applicable to other semiarid and arid regions in the world, including warm desert and semidesert, and other Mediterranean-climate areas. These regions are important because of their high plant diversity and, in Mediterraneanclimate regions, their high human population density. As climate change may aggravate water stress in these areas, studies focusing on the response of ecosystems to the change of soil water availability are essential for conservation studies and for natural resource management. The combination of flux tower data and remotely sensed data provides a novel strategy for examining the response of vegetation to soil-moisture fluctuations. The clear relationship between MODIS-derived VIs and soil moisture in the open grassland during the dry-down period indicates that remotely sensed data can detect soil water availability in shallowly rooted vegetation during the water-limited period. However, it is difficult to effectively use remotely sensed data to assess the response to soil water availability in ecosystems that are dominated by deeply rooted plants, because deeply rooted plants are less responsive to the short-term change of environmental variables. Within these limitations, it seems clear that incorporation of remotely sensed data in studies of vegetation response to declining soil water availability will expand the range of spatial scales and advance prediction of plant water stress in climate change scenarios.

\section{Acknowledgments}

This study was funded by Kearney Foundation of Soil Science, Award no. 2007.037, Modeling Soil Moisture in California at Multiple Scales. The authors are grateful to Dr. Baldocchi and his group for sharing measurements and providing comments on this paper and the VIPER Lab in the Department of Geography at University of California, Santa Barbara for providing MODIS composite images. Finally, they wish to thank two anonymous reviewers for their comments which greatly improved the paper.

\section{References}

[1] J. Major, "California Climate in relation to vegetation," in 'Terrestrial Vegetation of California', M. G. Barbour and J. Major, Eds., pp. 11-74, California Native Plant Society Special Publication 9, 1988.

[2] H. Walter, Ecology of Tropical and Subtropical Vegetation, Oliver and Boyd, Edinburgh, UK, 1971.

[3] R. J. Scholes and S. R. Archer, "Tree-grass interactions in Savannas," Annual Review of Ecology and Systematics, vol. 28, pp. 517-544, 1997.

[4] A. Kulmatiski, R. J. T. Verweij, K. H. Beard, and E. C. February, "A depth-controlled tracer technique measures vertical, horizontal and temporal patterns of water use by trees and grasses in a subtropical savanna," New Phytologist, vol. 188, no. 1, pp. 199-209, 2010.

[5] H. J. Schenk and R. B. Jackson, "Rooting depths, lateral root spreads and below-ground/above-ground allometries of plants in water-limited ecosystems," Journal of Ecology, vol. 90, no. 3, pp. 480-494, 2002.

[6] B. H. Walker, D. Ludwig, and S. Holling, "Stability of semi-arid savanna grazing systems," Journal of Ecology, vol. 69, no. 2, pp. 473-498, 1981.

[7] F. Van Langevelde, C. A. D. M. Van De Vijver, and L. Kumar, "Effects of fire and herbivory on the stability of savanna ecosystems," Ecology, vol. 84, no. 2, pp. 337-350, 2003.

[8] N. B. Thomas, "The control of stomata by water balance," New Phytologist, vol. 168, pp. 275-292, 2005.

[9] T. C. Hsiao, "Plant responses to water stress," Annual Review of Plant Physiology, vol. 24, pp. 519-570, 1973.

[10] H. K. Lichtenthaler, "Vegetation stress: an introduction to the stress concept in plants," Plant Physiology, vol. 148, pp. 4-14, 1996.

[11] O. E. Sala, W. J. Parton, L. A. Joyce, and W. K. Lauenroth, "Primary production of the central grassland region of the United States," Ecology, vol. 69, no. 1, pp. 40-45, 1988.

[12] C. Körner, Alpine Plant Life. In Functional Plant Ecology of High Mountain Ecosystems, Springer, Berlin, Germany, 1999.

[13] G. Maracci, G. Schmuck, B. Hosgood, and G. Andreoli, "Interpretation of reflectance spectra by plant physiological parameters," in Proceedings of the International Geoscience and Remote Sensing Symposium (IGARSS '91) Remote Sensing: Global Monitoring for Earth Management, pp. 2303-2306, Helsinki University of Technology, Espoo, Finland, June 1991.

[14] J. M. Briggs and A. K. Knapp, "Interannual variability in primary production in tallgrass prairie: climate, soil moisture, topographic position, and fire as determinants of aboveground biomass," American Journal of Botany, vol. 82, no. 8, pp. 1024-1030, 1995.

[15] A. K. Knapp and M. D. Smith, "Variation among biomes in temporal dynamics of aboveground primary production," Science, vol. 291, no. 5503, pp. 481-484, 2001.

[16] L. B. Flanagan, L. A. Wever, and P. J. Carlson, "Seasonal and interannual variation in carbon dioxide exchange and carbon balance in a northern temperate grassland," Global Change Biology, vol. 8, no. 7, pp. 599-615, 2002.

[17] L. Xu and D. D. Baldocchi, "Seasonal variation in carbon dioxide exchange over a Mediterranean annual grassland in California," Agricultural and Forest Meteorology, vol. 123, no. 1-2, pp. 79-96, 2004.

[18] A. C. Risch and D. A. Frank, "Carbon dioxide fluxes in a spatially and temporally heterogeneous temperate grassland," Oecologia, vol. 147, no. 2, pp. 291-302, 2006.

[19] D. D. Baldocchi, "Assessing the eddy covariance technique for evaluating carbon dioxide exchange rates of ecosystems: past, present and future," Global Change Biology, vol. 9, no. 4, pp. 479-492, 2003.

[20] A. K. Knapp, J. T. Fahnestock, S. P. Hamburg, L. B. Statland, T. R. Seastedt, and D. S. Schimel, "Landscape patterns in soil-plant water relations and primary production in tallgrass prairie," Ecology, vol. 74, no. 2, pp. 549-560, 1993.

[21] J. F. Reynolds, P. R. Kemp, K. Ogle, and R. J. Fernández, "Modifying the 'pulse-reserve' paradigm for deserts of North America: precipitation pulses, soil water, and plant responses," Oecologia, vol. 141, no. 2, pp. 194-210, 2004.

[22] A. Porporato, F. Laio, L. Ridolfi, and I. Rodriguez-Iturbe, "Plants in water-controlled ecosystems: active role in hydrologic processes and responce to water stress I. Scope and general outline," Advances in Water Resources, vol. 24, no. 7, pp. 695-705, 2001. 
[23] M. M. Chaves, J. S. Pereira, J. Maroco et al., "How plants cope with water stress in the field? Photosynthesis and growth," Annals of Botany, vol. 89, pp. 907-916, 2002.

[24] E. T. Engman and N. Chauhan, "Status of microwave soil moisture measurements with remote sensing," Remote Sensing of Environment, vol. 51, no. 1, pp. 189-198, 1995.

[25] M. C. Dobson and F. T. Ulaby, "Active microwave soil moisture research," IEEE Transactions on Geoscience and Remote Sensing, vol. 24, no. 1, pp. 23-36, 2007.

[26] T. Schmugge, P. E. O’Neill, and J. R. Wang, "Passive microwave soil moisture research," IEEE Transactions on Geoscience and Remote Sensing, vol. 24, no. 1, pp. 12-22, 2007.

[27] J. A. Gamon, B. Field, M. L. Goulden et al., "Relationships between NDVI, canopy structure, and photosynthesis in three Californian vegetation types," Ecological Applications, vol. 5, no. 1, pp. 28-41, 1995.

[28] A. A. Gitelson and M. N. Merzlyak, "Signature analysis of leaf reflectance spectra: algorithm development for remote sensing of chlorophyll," Journal of Plant Physiology, vol. 148, no. 3-4, pp. 494-500, 1996.

[29] E. R. Hunt and B. N. Rock, "Detection of changes in leaf water content using Near- and Middle-Infrared reflectances," Remote Sensing of Environment, vol. 30, no. 1, pp. 43-54, 1989.

[30] T. J. Jackson, D. Chen, M. Cosh et al., "Vegetation water content mapping using landsat data derived normalized difference water index for corn and soybeans," Remote Sensing of Environment, vol. 92, no. 4, pp. 475-482, 2004.

[31] T. J. Farrar, S. E. Nicholson, and A. R. Lare, "The influence of soil type on the relationships between NDVI, rainfall, and soil moisture in semiarid Botswana. II.NDVI response to soil moisture," Remote Sensing of Environment, vol. 50, no. 2, pp. 121-133, 1994.

[32] P. E. Dennison, D. A. Roberts, S. R. Thorgusen, J. C. Regelbrugge, D. Weise, and C. Lee, "Modeling seasonal changes in live fuel moisture and equivalent water thickness using a cumulative water balance index," Remote Sensing of Environment, vol. 88, no. 4, pp. 442-452, 2003.

[33] D. A. Roberts, S. L. Ustin, S. Ogunjemiyo et al., "Spectral and structural measures of northwest forest vegetation at leaf to landscape scales," Ecosystems, vol. 7, no. 5, pp. 545-562, 2004.

[34] J. O. Adegoke and A. M. Carleton, "Relations between soil moisture and satellite vegetation indices in the U.S. Corn Belt," American Meteorology Society, vol. 3, no. 4, pp. 395-405, 2001.

[35] Y. Gu, E. Hunt, B. Wardlow, J. B. Basara, J. F. Brown, and J. P. Verdin, "Evaluation of MODIS NDVI and NDWI for vegetation drought monitoring using Oklahoma Mesonet soil moisture data," Geophysical Research Letters, vol. 35, no. 22, Article ID L22401, 2008.

[36] R. R. Gillies, T. N. Carlson, J. Cui, W. P. Kustas, and K. S. Humes, "A verification of the 'triangle' method for obtaining surface soil water content and energy fluxes from remote measurements of NDVI and surface radiant temperature ," International Journal of Remote Sensing, vol. 18, no. 15, pp. 3145-3166, 1997.

[37] I. Sandholt, K. Rasmussen, and J. Andersen, "A simple interpretation of the surface temperature/vegetation index space for assessment of surface moisture status," Remote Sensing of Environment, vol. 79, no. 2-3, pp. 213-224, 2002.

[38] K. Mallick, B. K. Bhattacharya, and N. K. Patel, "Estimating volumetric surface moisture content for cropped soils using a soil wetness index based on surface temperature and NDVI," Agricultural and Forest Meteorology, vol. 149, no. 8, pp. 13271342, 2009.
[39] I. Rodriguez-Iturbe, "Ecohydrology: a hydrologic perspective of climate-soil-vegetation dynamics," Water Resources Research, vol. 36, no. 1, pp. 3-9, 2000.

[40] S. Ma, D. D. Baldocchi, L. Xu, and T. Hehn, "Inter-annual variability in carbon dioxide exchange of an oak/grass savanna and open grassland in California," Agricultural and Forest Meteorology, vol. 147, no. 3-4, pp. 157-171, 2007.

[41] L. Xu, D. D. Baldocchi, and J. Tang, "How soil moisture, rain pulses, and growth alter the response of ecosystem respiration to temperature," Global Biogeochemical Cycles, vol. 18, pp. 4002-4012, 2004.

[42] D. D. Baldocchi, L. Xu, and N. Kiang, "How plant functionaltype, weather, seasonal drought, and soil physical properties alter water and energy fluxes of an oak-grass savanna and an annual grassland," Agricultural and Forest Meteorology, vol. 123, no. 1-2, pp. 13-39, 2004.

[43] P. E. Dennison, D. A. Roberts, and S. H. Peterson, "Spectral shape-based temporal compositing algorithms for MODIS surface reflectance data," Remote Sensing of Environment, vol. 109, pp. 510-522, 2007.

[44] J. W. Rouse, R. H. Haas, J. A. Schell, and D. W. Deering, "Monitoring vegetation system in the great plains with ERTS," in Proceedings of the 3rd ERTS Symposium, vol. 1 of NASA SP351, pp. 309-317, NASA, Washington, DC, USA, 1973.

[45] A. A. Gitelson, Y. J. Kaufman, R. Stark, and D. Rundquist, "Novel algorithms for remote estimation of vegetation fraction," Remote Sensing of Environment, vol. 80, no. 1, pp. 76-87, 2002.

[46] B. C. Gao, "NDWI-A normalized difference water index for remote sensing of vegetation liquid water from space," Remote Sensing of Environment, vol. 58, no. 3, pp. 257-266, 1996.

[47] A. Palacios-Orueta, S. Khanna, J. Litago, M. L. Whiting, and S. L. Ustin, "Assessment of NDVI and NDWI spectral indices using MODIS time series analysis and development of a new spectral index based on MODIS shortwave infrared bands," in Proceedings of the 1st International Conference of Remote Sensing and Geoinformation Processing, pp. 207-209, Trier, Germany, 2006.

[48] J. A. Gamon, C. B. Field, M. L. Goulden et al., "Relationships between NDVI, canopy structure, and photosynthesis in three Californian vegetation types," Ecological Applications, vol. 5, no. 1, pp. 28-41, 1995.

[49] J. M. Paruelo, H. E. Epstein, W. K. Lauenroth, and I. C. Burke, "ANPP estimates from NDVI for the central grassland region of the United States," Ecology, vol. 78, no. 3, pp. 953-958, 1997.

[50] M. L. Whiting, L. Li, and S. L. Ustin, "Predicting water content using Gaussian model on soil spectra," Remote Sensing of Environment, vol. 89, no. 4, pp. 535-552, 2004.

[51] S. Khanna, A. Palacios-Orueta, M. L. Whiting, S. L. Ustin, D. Riaño, and J. Litago, "Development of angle indexes for soil moisture estimation, dry matter detection and land-cover discrimination," Remote Sensing of Environment, vol. 109, no. 2, pp. 154-165, 2007.

[52] M. M. Caldwell, T. E. Dawson, and J. H. Richards, "Hydraulic lift: consequences of water efflux from the roots of plants," Oecologia, vol. 113, no. 2, pp. 151-161, 1998.

[53] M. A. Davis, K. J. Wrage, and P. B. Reich, "Competition between tree seedlings and herbaceous vegetation: support for a theory of resource supply and demand," Journal of Ecology, vol. 86, no. 4, pp. 652-661, 1998.

[54] R. S. Oliveira, L. Bezerra, E. A. Davidson et al., "Deep root function in soil water dynamics in cerrado savannas of central Brazil," Functional Ecology, vol. 19, no. 4, pp. 574-581, 2005. 
[55] S. Jacquemoud, "Inversion of the PROSPECT + SAIL canopy reflectance model from AVIRIS equivalent spectra: theoretical study," Remote Sensing of Environment, vol. 44, no. 2-3, pp. 281-292, 1993.

[56] H. Bach and W. Verhoef, "Sensitivity studies on the effect of surface soil moisture on canopy reflectance using the radiative transfer model GeoSAIL," in Proceedings IEEE International Geoscience and Remote Sensing Symposium (IGARSS '03), pp. 1679-1681, Toulouse, France, July 2003.

[57] L. Wang, J. J. Qu, X. Hao, and Q. Zhu, "Sensitivity studies of the moisture effects on MODIS SWIR reflectance and vegetation water indices," International Journal of Remote Sensing, vol. 29, no. 24, pp. 7065-7075, 2008.

[58] G. Rondeaux, M. Steven, and F. Baret, "Optimization of soiladjusted vegetation indices," Remote Sensing of Environment, vol. 55, no. 2, pp. 95-107, 1996. 

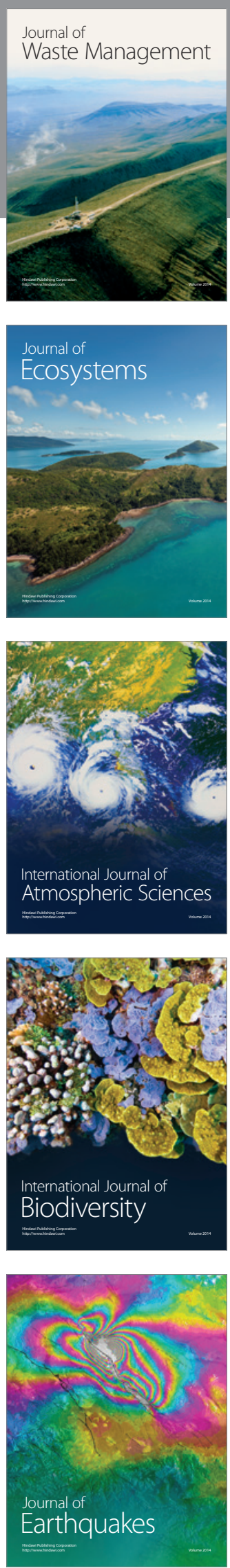
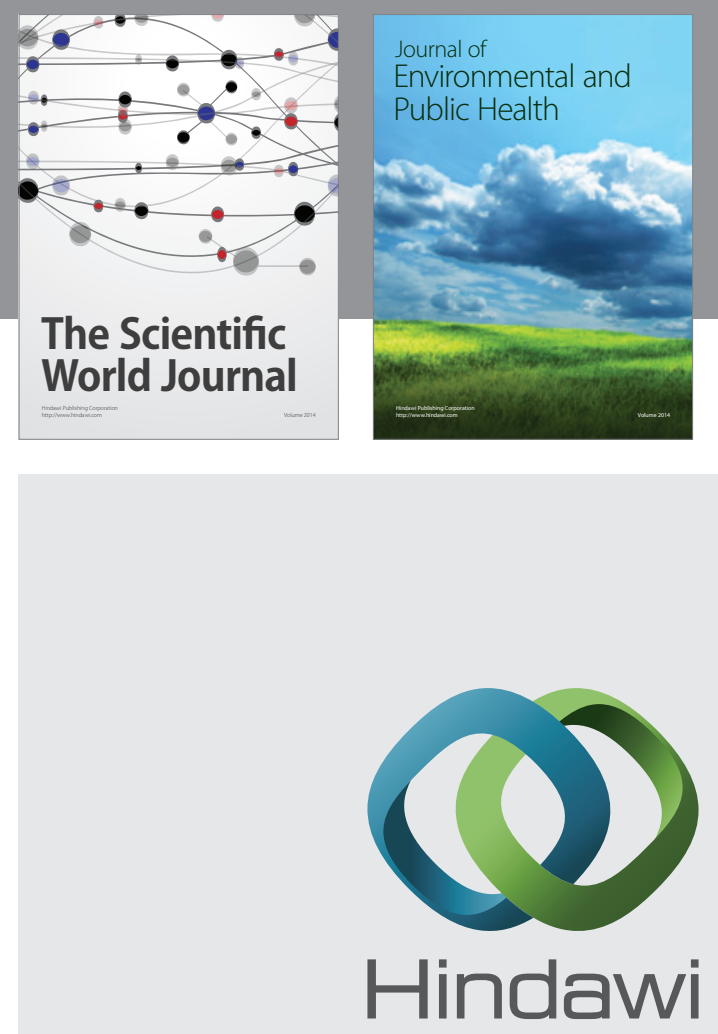

Submit your manuscripts at

http://www.hindawi.com
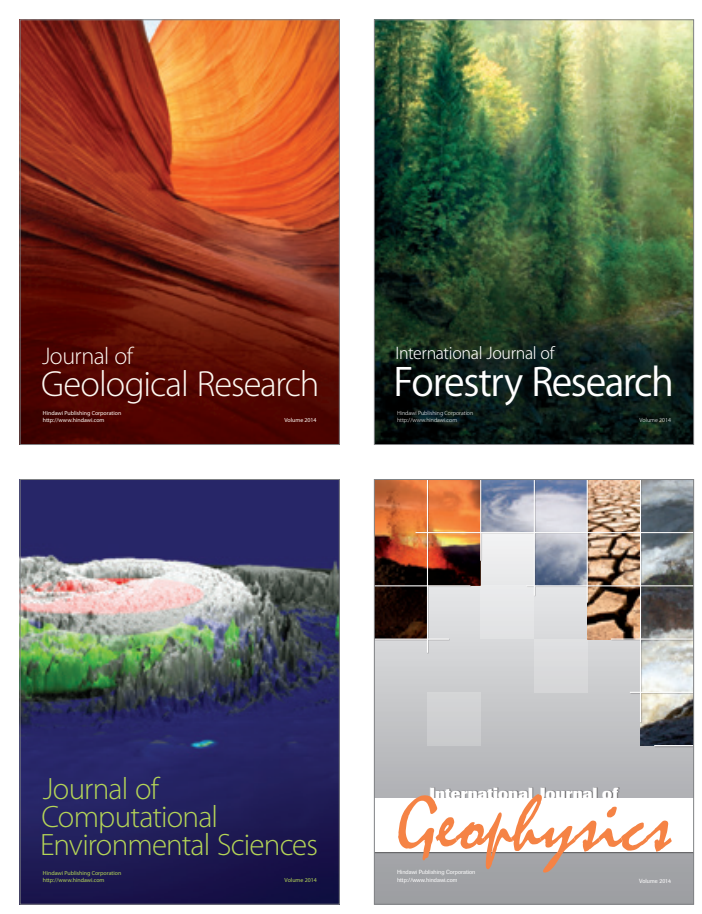
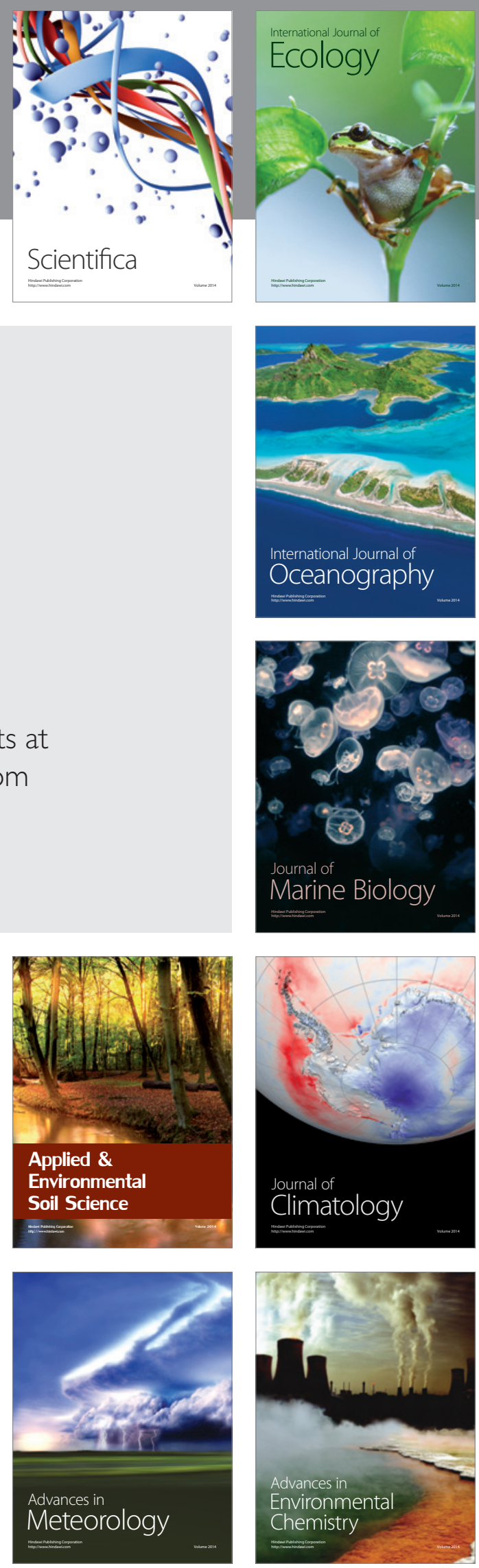